\title{
PENGARUH PENDIDIKAN KESEHATAN TERHADAP PENGETAHUAN SISWA TENTANG PERILAKU HIDUP BERSIH DAN SEHAT (PHBS)
}

\author{
The Effect Of Health Education On Students 'Knowledge Of Clean And Healthy Living \\ Behaviors (PHBS)
}

Sofa Qurrata A'yun ${ }^{1}$, Ervi Suminar ${ }^{2}$, Fardah Etsa Maulani ${ }^{3}$

${ }^{1}$ Program Studi S1 Kebidanan STIKES Husada Jombang

${ }^{2}$ Program Studi Ilmu Keperawatan Universitas Muhammadiyah Gresik

${ }^{3}$ Program Studi IImu Keperawatan STIKES Insan Seagung Bangkalan

\author{
Alamat Korespondensi : Prodi S1 Kebidanan Stikes Husada Jombang \\ Jl. Veteran, Mancar Peterongan Jombang, Jawa Timur - Indonesia \\ Email : Shova.ayuni@gmail.com
}

\begin{abstract}
ABSTRAK
PHBS di sekolah merupakan sekumpulan perilaku yang dipraktikkan oleh peserta didik, guru, dan masyarakat lingkungan sekolah atas dasar kesadaran sebagai hasil pembelajaran, sehingga secara mandiri mampu mencegah penyakit, meningkatkan kesehatannya, serta berperan aktif dalam mewujudkan lingkungan sehat. Anak usia sekolah rentan terhadap masalah kesehatan dan perubahan, masalah ini kurang diperhatikan oleh orang tua dan pihak sekolah. Padahal peranan mereka mempengaruhi kualitas hidup anak di kemudian hari. Tujuan penelitian ini adalah mengetahui pengaruh pendidikan kesehatan terhadap pengetahuan siswa tentang PHBS.

Dalam penelitian ini rancangan penelitian yang digunakan adalah rancangan eksperimental dengan one-group pre test-post test design, populasinya semua siswa di SDN Kraton 5 Bangkalan sebanyak 207 siswa, sedangkan sampel yang di ambil sebanyak 136 siswa secara simple random sampling. Variabel penelitiannya adalah PHBS dan pendidikan kesehatan. Metode pengumpulan data penelitian ini menggunakan kuesioner dan dianalisa menggunakan uji Wilcoxon Signed Rank.

Hasil penelitian menunjukkan pengetahuan siswa sebelum dilakukan pendidikan kesehatan sebagian besar adalah kurang sebanyak 63 siswa $(46,2 \%)$ dan pengetahuan siswa setelah dilakukan pendidikan kesehatan sebagian besar adalah baik yaitu sebanyak 58 siswa (50\%). Pada analisa Wilcoxon Signed Rank menunjukkan ada pengaruh pendidikan kesehatan terhadap pengetahuan siswa tentang PHBS di SDN Kraton 5 Bangkalan $(\mathrm{p}=0.000<\alpha=0.05)$.

Berdasarkan hasil penelitian, maka diharapkan bagi tenaga kesehatan dapat mendekatkan pelayanan dengan mengaktifkan kunjungan ke sekolah dan memberikan pendidikan kesehatan yang berkala khususnya tentang PHBS agar siswa mengerti dan dapat menerapkan kebiasaan dalam melaksanakan PHBS.
\end{abstract}

\section{Kata Kunci: PHBS, Pendidikan Kesehatan, Pengetahuan}

\begin{abstract}
PHBS in school is a group of behaviors that is practiced by learners, teachers, and the public of the school environment based on awareness as a result of learning, so that it is able to prevent disease independently, improve health, and have an active role in realizing a healthy environment. School-aged children are susceptible to health problems and changes, these issues are cared less by parents and the school. Whereas their role affect the quality of life of children in the future. The purpose of this research is to know the effect of health education on the students' knowledge about PHBS.

In this research, the research design used experimental with one-group pre test-post test design, the population was all of students in SDN Kraton 5 Bangkalan as many as 207 students, while the sample was taken as many as 136 students in simple random sampling. The research variables are PHBS and health education. The method of data collection of this study was using questionnaires and analyzed using Wilcoxon Signed Rank test.
\end{abstract}


The result of the research showed that the students' knowledge before doing the health education was less than 63 students (46,2\%) and the students' knowledge after doing the health education mostly was good that is 68 students (50\%). In the Wilcoxon Signed Rank analysis showed there was an effect of health education on the students' knowledge about PHBS at SDN Kraton 5 Bangkalan $(p=0.000<\alpha=0.05) . z$

Based on the results of this research, it is expected that health workers can approach the service by enabling visits to schools and providing periodic health education especially about PHBS so that the students understand and can apply the practice in implementing PHBS.

\section{Keywords: PHBS, Health Education, Knowledge}

\section{PENDAHULUAN}

Derajat kesehatan anak pada saat ini belum bisa dikatakan baik karena masih banyak terdapat masalah kesehatan khususnya pada anak usia sekolah. Anak usia sekolah merupakan kelompok usia sekolah yang kritis karena pada usia tersebut rentan terhadap masalah kesehatan. Anak usia sekolah selain rentan terhadap masalah kesehatan juga peka terhadap perubahan. Masalah ini kurang begitu diperhatikan baik oleh orang tua, sekolah atau para klinisi serta professional kesehatan lainnya yang saat ini masih memprioritaskan kesehatan anak balita. Padahal peranan mereka sangat dominan akan mempengaruhi kualitas hidup anak di kemudian hari.

Upaya untuk meningkatkan kesadaran, kemauan dan kemampuan hidup sehat perlu diadakannya pendidikan kesehatan. Sekarang ini pendidikan kesehatan kurang dilibatkan dalam program-program pelayanan kesehatan, padahal dengan adanya pendidikan kesehatan dapat meningkatkan pengetahuan anak yang dapat berpengaruh kepada perilaku sebagai hasil jangka menengah. Selanjutnya perilaku kesehatan akan berpengaruh pada meningkatnya indikator kesehatan masyarakat terutama pada anak.

Berdasarkan hasil studi pendahuluan di SDN Kraton 5 Bangkalan dengan menggunakan tehnik wawancara pada 10 siswa tentang PHBS didapatkan 4 siswa (40\%) dikategorikan cukup dan 6 siswa (60\%) dikategorikan kurang dalam kriteria pengetahuan PHBS.

Kondisi tersebut harus segera diantisipasi dengan meningkatkan pola hidup sehat melalui PHBS. Upaya sosialisasi dapat dilakukan dengan pengenalan konsep PHBS mulai dari lingkungan keluarga hingga institusi pendidikan (Umiziah, 2016). Anak sekolah merupakan generasi penerus bangsa yang perlu dijaga, ditingkatkan dan dilindungi kesehatannya. Jumlah usia sekolah yang cukup besar dari jumlah penduduk Indonesia merupakan masa keemasan untuk menanamkan Perilaku Hidup Bersih dan Sehat (PHBS) sehingga anak sekolah berpotensi sebagai agen perubahan untuk mempromosikan PHBS, baik di lingkungan sekolah, keluarga maupun masyarakat (Proverawati \& Rahmawati, 2012).

Dampak dari pengetahuan dan pemahaman yang kurang tentang PHBS diduga menjadi salah satu faktor penyebab 
tingginya kasus penyebaran penyakit menular seperti diare, DBD, dan lain-lain. Oleh karena itu diperlukan upaya pendidikan kesehatan untuk meningkatkan pengetahuan siswa pada khususnya dan masyarakat pada umumnya. Setelah mendapatkan pendidikan kesehatan siswa dapat memperkenalkan (mempromosikan) PHBS pada keluarga di rumah, sehingga secara tidak langsung dapat meningkatkan derajat kesehatan masyarakat. Oleh karena itu, peneliti tertarik untuk menganalisis "Pengaruh Pendidikan Kesehatan Terhadap Pengetahuan Siswa tentang PHBS di SDN Kraton 5 Bangkalan"

\section{METODE}

Jenis penelitian ini adalah penelitian eksperimental dengan rancangan one-group pre test-post test design, populasinya semua siswa di SDN Kraton 5 Bangkalan sebanyak 207 siswa, sedangkan sampel yang di ambil sebanyak 136 siswa secara simple random sampling. Variabel penelitiannya adalah PHBS dan pendidikan kesehatan. Metode pengumpulan data penelitian ini menggunakan kuesioner dan dianalisa menggunakan uji Wilcoxon Signed Rank.

\section{HASIL DAN PEMBAHASAN}

1. Pengetahuan Siswa Tentang PHBS Sebelum Dilakukan Pendidikan Kesehatan

\section{Tabel 1. Distribusi Frekuensi Pengetahuan} Tentang PHBS Sebelum Dilakukan Pendidikan Kesehatan Di SDN Kraton 5 Bangkalan April 2017

\begin{tabular}{|c|c|c|}
\hline Kriteria & Frekuensi & Persentase (\%) \\
\hline Baik & 31 & $23,1 \%$ \\
\hline Cukup & 42 & $30,7 \%$ \\
\hline Kurang & 63 & $46,2 \%$ \\
\hline Total & 136 & $100 \%$ \\
\hline
\end{tabular}

bahwa pengetahuan siswa sebelum dilakukan pendidikan kesehatan adalah berpengetahuan kurang yaitu sebanyak 63 siswa (46,2\%).

Hal ini dikarenakan pengetahuan merupakan hasil tahu seseorang dan ini terjadi setelah seseorang melakukan penginderaan terhadap suatu subyek tertentu (Notoatmodjo, 2011a).

Menurut Notoatmodjo, sekolah juga perlu melaksanakan pembinaan lingkungan sekolah sehat (Notoatmodjo, 2012). Lingkungan sekolah yang sehat merupakan faktor bagi terwujudnya perilaku yang sehat. Meskipun siswa-siswa telah mengetahui dan memahami bahwa buang sampah harus di tempatnya, buang air kecil atau air besar harus di WC sekolah, tetapi kalau di lingkungan sekolah tidak ada tempat sampah atau WC sekolah, maka siswa tersebut akan membuang sampah di sembarang tempat. Lingkungan sekolah harus kondusif untuk perilaku hidup sehat, atau mempunyai fasilitas lingkungan yang mendukung perilaku hidup sehat.

Hasil penelitian ini sesuai dengan penelitian yang dilakukan oleh Lucky Dwi Umiziah, 2016 dengan judul pengaruh pendidikan kesehatan terhadap pengetahuan dan sikap tentang perilaku hidup bersih dan sehat (PHBS) pada siswa SMP Muhammadiyah 1 Kartasura, Kabupaten 
Sukoharjo, Jawa Tengah. Hasil penelitian menunjukkan bahwa pengetahuan PHBS sebelum diberikan pendidikan kesehatan (pre-test) pada siswa kelas VIII SMP Muhammadiyah 1 Kartasura mayoritas termasuk kategori kurang yaitu sebanyak 84,4\%, kemudian kategori cukup sebanyak $15,6 \%$, dan tidak ada yang termasuk kategori baik (Umiziah, 2016). Hal ini menunjukkan masih banyak responden yang belum mendapat pengetahuan yang baik terhadap perilaku hidup bersih dan sehat dikarenakan kurangnya informasi yang diberikan oleh pihak sekolah tentang perilaku hidup bersih dan sehat.

Selain itu, usia juga mempengaruhi tingkat pengetahuan. Semakin cukup umur, tingkat kematangan dan kekuatan seseorang akan lebih matang dalam berfikir dan bekerja (Notoatmodjo, 2011b). Usia yang semakin tinggi maka semakin banyak pula pengalaman yang dimiliki. Pengalaman adalah kejadian yang pernah dialami seseorang dalam berinteraksi dengan lingkungannya. Hal ini sesuai dengan hasil penelitian yaitu mayoritas responden adalah berumur $10-11$ tahun yaitu sebanyak 47 siswa $(34,6 \%)$.

$$
\text { Menurut pendapat peneliti }
$$
pengetahuan yang baik juga dipengaruhi oleh lingkungan budaya dimana yang dimaksud adalah lingkungan sekolah. Pihak sekolah yang tidak memberikan pendidikan kesehatan tentang PHBS itu sendiri pada siswa serta kurangnya sarana dan prasarana yang di sediakan pihak sekolah seperti jarang terdapat poster tentang PHBS, jarang adanya tempat sampah dan kurangnya fasilitas kamar mandi seperti tidak adanya sabun dan air kamar mandi yang kotor.

Jadi dari pihak sekolah seharusnya dapat memberikan pendidikan kesehatan terutama tentang PHBS serta disediakannya sarana dan prasarana seperti poster tentang PHBS, kurangnya tempat sampah dan kurangnya fasilitas yang terdapat dikamar mandi

\section{Pengetahuan Siswa Tentang PHBS Setelah dilakukan Pendidikan Kesehatan}

Tabel 2.Distribusi Frekuensi Pengetahuan Tentang PHBS Setelah Dilakukan Pendidikan Kesehatan Di SDN Kraton 5 Bangkalan April 2017

\begin{tabular}{lll}
\hline Kriteria & Frekuensi & $\begin{array}{l}\text { Persentase } \\
(\mathbf{\%})\end{array}$ \\
\hline Baik & 68 & $50 \%$ \\
\hline Cukup & 37 & $26,9 \%$ \\
\hline Kurang & 31 & $23,1 \%$ \\
\hline Total & $\mathbf{1 3 6}$ & $\mathbf{1 0 0 \%}$ \\
\hline
\end{tabular}

Tabel 2 menunjukkan bahwa pengetahuan siswa tentang perilaku hidup bersih dan sehat sesudah dilakukan pendidikan kesehatan berpengetahuan baik yaitu sebanyak 68 siswa (50\%). Hal ini disebabkan oleh kemampuan siswa yang berbeda dalam menyerap informasi yang diberikan.

Perubahan pengetahuan tersebut dapat dilakukan melalui pemberian pendidikan kesehatan, dimana tujuan pendidikan kesehatan itu sendiri adalah menanamkan pengetahuan dengan harapan agar pengetahuan tersebut membentuk sikap yang pada gilirannnya akan mempengaruhi perilaku (Pickett, 2009). 
Sebagian besar pengetahuan manusia diperoleh melalui mata dan telinga, salah satu faktor yang mempengaruhi pengetahuan adalah informasi. Informasi yang didapatkan oleh siswa tentang perilaku hidup bersih dan sehat dapat diperoleh melalui pendidikan kesehatan tentang perilaku hidup bersih dan sehat yang menyebabkan mereka tahu tentang perilaku hidup bersih dan sehat (Notoatmodjo, 2011a).

Pendidikan kesehatan dapat memberikan segala macam informasi yang mereka butuhkan. Mulai dari informasi yang sederhana sampai informasi yang penting. Pada awalnya siswa tidak mengetahui apa itu perilaku hidup bersih dan sehat, namun setelah dilakukan pendidikan kesehatan mereka mengetahui semua informasi tentang perilaku hidup bersih dan sehat, seperti pengertian perilaku hidup bersih dan sehat, manfaat perilaku hidup bersih dan sehat, serta indikator-indikator perilaku hidup bersih dan sehat.

Hasil penelitian ini sesuai dengan penelitian yang dilakukan oleh Lucky Dwi Umiziah, 2016 dengan judul pengaruh pendidikan kesehatan terhadap pengetahuan dan sikap tentang perilaku hidup bersih dan sehat (PHBS) pada siswa SMP Muhammadiyah 1 Kartasura, Kabupaten Sukoharjo, Jawa Tengah. Hasil penelitian menunjukkan bahwa pengetahuan PHBS sesudah diberikan pendidikan kesehatan (post-test) pada siswa kelas VIII SMP Muhammadiyah 1 Kartasura mayoritas termasuk kategori baik yaitu sebanyak $62,5 \%$, kategori cukup sebanyak 31,2\%, dan yang kategori kurang hanya 6,3\%. Hasil pengkategorian pada periode setelah pendidikan kesehatan menunjukkan bahwa tingkat pengetahuan responden sudah meningkat dengan mayoritas pengetahuan yang termasuk kategori baik (Umiziah, 2016). Hal ini menunjukkan bahwa pendidikan kesehatan mempengaruhi pengetahuan siswa tentang PHBS sehingga responden dikemudian hari dapat melaksanakan PHBS dengan baik.

Dari hasil kesimpulan dapat disimpulkan bahwa dengan memberikan pendidikan kesehatan, siswa dapat mendapatkan informasi tentang perilaku hidup bersih dan sehat. Pendidikan kesehatan menjadi hal yang menentukan dalam kemampuan seseorang dalam melakukan pencegahan timbulnya penyakit dengan perilaku hidup bersih dan sehat.

Melalui kegiatan pendidikan kesehatan, maka siswa dapat menyebarluaskan informasi yang diterima kepada keluarga dan lingkungan sosialnya. Muatan pendidikan kesehatan tersebut disesuaikan dengan karakter perilaku yang dapat dipandang sebagai faktor resiko terhadap kesehatan anak sekolah. Misalnya pada penelitian ini, siswa yang diberikan pendidikan kesehatan dapat memahami dan dapat melaksanakan informasi yang didapatkan dari pendidikan ksehatan tentang perilaku hidup bersih dan sehat (PHBS). 


\section{Pengaruh Pendidikan Kesehatan terhadap Pengetahuan Siswa tentang Perilaku Hidup Bersih dan Sehat (PHBS)}

Berdasarkan hasil penelitian yang dilakukan di SDN Kraton 5 Bangkalan diketahui bahwa mayoritas frekuensi pengetahuan tentang PHBS siswa sebelum dilakukan pendidikan kesehatan adalah kurang sebanyak 63 siswa $(46,2 \%)$ dan mayoritas frekuensi pengetahuan tentang PHBS siswa sesudah dilakukan pendidikan kesehatan adalah baik sebanyak 68 siswa(50\%). Berdasarkan uji statistik dengan menggunakan uji Wilcoxon Signed Ranks Test didapatkan nilai $\rho=0,000<\alpha=0,05$, maka H0 ditolak dan H1 diterima dengan demikian ada pengaruh pendidikan kesehatan terhadap pengetahuan siswa tentang perilaku hidup bersih dan sehat (PHBS).

Hal tersebut membuktikan bahwa pengetahuan siswa tentang perilaku hidup bersih sehat lebih baik sesudah dilakukan pendidikan kesehatan tentang PHBS dibandingkan dengan pengetahuan siswa tentang perilaku hidup bersih dan sehat sebelum dilakukan pendidikan kesehatan. Karena pendidikan kesehatan adalah segala upaya yang direncanakan untuik mempengaruhi orang lain, baik individu, kelompok, atau masyarakat, sehingga mereka melakukan apa yang diharapkan oleh pelaku pendidikan kesehatan (Notoatmodjo, 2011a).

Hal ini konsisten dengan hasil penelitian Lubis yang dilakukan di SDN 065014 Kelurahan Namogajah Kecamatan Medan Tuntungan Koa Medan dengan hasil nilai probabilitas pengetahuan ( $\rho$ ) 0,0001 dan probabilitas tersebut $\rho<0,05$ yang membuktikan bahwa pemberian pendidikan kesehatan dapat meningkatkan pegetahuan tentang perilaku hidup bersih dan sehat (Lubis et al., 2013). Metode yang digunakan dalam pemberian pendidikan kesehatan mampu meningkatkan sikap ke arah perilaku yang positif. Salah satu starategi untuk perubahan perilaku adalah pemberian informasi guna meningkatkan pengetahuan sehingga timbul kesadaran yang pada akhirnya orang akan berperilaku sesuai dengan pengetahuannya tersebut. Salah satu upaya pemberian informasi yang dapat dilakukan adalah penyuluhan (Notoatmodjo, 2011b).

Peningkatan pengetahuan dipengaruhi oleh metode dalam pemberian pendidikan kesehatan yang mudah diterima yaitu dengan metode ceramah dan tanya jawab serta menggunakan media flipchart dengan pemberian gambar yang menarik dan leaflet. Dengan demikian dapat meningkatkan ketertarikan siswa pada saat diberikan pendidikan kesehatan. Pendidikan kesehatan akan lebih efektif dan efisien jika menggunakan media yang menarik dan menunjang secara optimal pada proses pembelajaran.

Menurut pendapat peneliti bahwa pendidikan kesehatan dapat mempengaruhi luas tidaknya pengetahuan siswa tentang perilaku hidup bersih dan sehat, dengan demikian diharapkan petugas kesehatan dan juga pihak sekolah untuk lebih sering mengadakan pendidikan kesehatan kepada 
siswa tentang perilaku hidup bersih dan sehat sehingga siswa memiliki pengetahuan yang cukup memadai tentang perilaku hidup bersih dan sehat. Selain itu dari pihak sekolah dapat memberikan edukasi yang lebih baik dan banyak kepada siswanya, baik melalui poster ataupun lainnya, berkaitan dengan pengoptimalan implementasi trias UKS yaitu melaksanakan pendidikan kesehatan di sekolah dan madrasah, menyelenggarakan pelayanan kesehatan di sekolah dan madrasah, dan menciptakan lingkungan kehidupan sekolah dan madrasah yang Sehat.

\section{KESIMPULAN}

Ada pengaruh pendidikan kesehatan terhadap pengetahuan siswa tentang perilaku hidup bersih dan sehat.

\section{SARAN}

Setelah dilakukan pendidikan tentang PHBS sekolah dapat menerapkan perilaku hidup bersih sehat secara berkesinambungan sehingga seluruh warga sekolah mendapatkan kesehatan yang baik dan lebih berwawasan tentang PHBS.

\section{DAFTAR PUSTAKA}

Lubis, Z. S. A., Lubis, N. L., \& Syahrial, E. (2013). Pengaruh Penyuluhan Dengan Metode Ceramah Dan Diskusi Terhadap Peningkatan Penfetahuan Dan Sikap Anak Tentang PHBS Di Sekolah Dasar Negeri 065014 Kelurahan Namogajah Kecamatan Medan Tuntungan. PPKIS Universitas Sumatera Utara. https://media.neliti.com/media/publicati ons/14398-ID-pengaruh-penyuluhandengan-metode-ceramah-dan-diskusiterhadap-peningkatan-penge.pdf
Notoatmodjo, S. (2011a). Ilmu Perilaku Kesehatan. Rineka Cipta.

Notoatmodjo, S. (2011b). Kesehatan Masyarakat: Ilmu dan Seni Edisi Revisi. Rineka Cipta.

Notoatmodjo, S. (2012). Promosi Kesehatan Di Sekolah. Pusat Promosi Kesehatan Departemen Kesehatan Republik Indonesia.

Pickett, D. (2009). Kesehatan Masyarakat: Administrasi dan Praktek. EGC.

Proverawati, A., \& Rahmawati, A. (2012). Perilaku Hidup Bersih dan Sehat (PHBS). Nuha Medika.

Umiziah, L. D. (2016). PENGARUH PENDIDIKAN KESEHATAN TERHADAP PENGETAHUAN DAN SIKAP TENTANG PERILAKU HIDUP BERSIH DAN SEHAT (PHBS) PADA SISWA SMP MUHAMMADIYAH 1 KARTASURA [Universitas Muhammadiyah Surakarta]. http://eprints.ums.ac.id/42020/1/NASK AH PUBLIKASI.pdf 